\title{
Superplastic forming of shells from sheet blanks with thermally unstable coatings
}

\author{
Aleksandr Anishchenko ${ }^{1}$, Volodymyr Kukhar ${ }^{1}$, Viktor Artiukh ${ }^{2,}$ and and Olga Arkhipova ${ }^{3}$ \\ ${ }^{1}$ Pryazovskyi State Technical University, Universytetska, 7, Mariupol, 87555, Ukraine \\ ${ }^{2}$ Peter the Great St. Petersburg Polytechnic University, Polytechnicheskaya, 29, St.Petersburg, \\ 195251, Russia \\ ${ }^{3}$ Tyumen Industrial University, Volodarskogo str., 38, Tyumen, 625000, Russia
}

\begin{abstract}
The article is devoted to superplastic forming of non-uniformly heated sheet blanks from aluminum alloy $A M g 6 M$. To create an uneven temperature field over the surface of the blank, coatings made of sublimated substances were used from at temperatures $50 \ldots 150^{\circ} \mathrm{C}$ below the superplastic forming temperature $\left(450^{\circ} \mathrm{C}\right.$ for $A M g 6 M$ alloy). An aqueous solute of chloride and ammonium iodide having a sublimation temperature at normal pressure and a latent heat of conversion equal to 338 and $404^{\circ} \mathrm{C}, 330$ and $355 \mathrm{~kJ} / \mathrm{kg}$, respectively, was sprayed onto the central zones of the blanks. Superplastic forming of shells was carried out in two modes: 1) with simultaneous sublimation of the coating; 2) with the beginning of the sublimation of the coating upon reaching the height, which is formed by the workpiece, equal to $20-30 \%$ of the final shell height. The experiments showed a decrease in the thickness of the shells to be formed up to $4-10 \%$ on the working surface of the shells (without taking into account their flange zones) and the savings of sublimate during superplastic forming in the second mode. The optimal subliming coating for $A M g 6 M$ alloy was ammonium chloride.
\end{abstract}

\section{Introduction}

The main disadvantage of the process of shells superplastic forming (SPF) from sheet blanks [1-3] is the large variability of the walls along the contour of products. So the thickness of the wall in the pole ("crown") of the hemisphere varies between $40 . . .70 \%$ of the initial thickness of the blank. There are a number of ways to regulate the metal flow during plastic forming, in particular, elimination of products thickness variability. They provide the preliminary profiling of the blank or semi-finished product, changing the structure of the metal of the blank and the face friction conditions at the "workpiece-die" border, and SPF in an uneven temperature field.

Preforming of semi-finished product is the most common way in the industry to control its thickness $[4,5]$. SPF process in this case provides, as a rule, two-stage molding by pneumomechanical (PMF) or reversible forming (RF) methods. The deep drawing by a metal punch with the maximum thinning of the peripheral zones of the blank is added to the

\footnotetext{
*Corresponding author: artiukh@mail.ru
} 
gas forming (before or after SPF) with a predominant refinement of the central zones of the blank [6-10]. As a result, the thickness distribution in the product is close to uniform.

RF of shells [10-16] on the first stage is carried out into the cavity of the rift along its contour, selected in such a way that the zones of the preform near the flange are deformed most intensively. At the second stage, when the gas pressure is reversed, the semi-finished product is formed into the cavity of the die with the predominant thinning of its central part.

Pre-profiling of the initial blanks involves stamping the blanks with an increase in the thickness of the metal in places that are maximally thinning with further SPF [17-19]. In this case, with the same strain degrees of the shell, the absolute value of the wall thickness will be close to the wall thickness in the zones of small strain.

The change in the structure of the blank's metal assumes the formation of grains of various sizes in the required places [2, 20-23]. Most often in preforms with a prepared superplastic structure in the zones with the maximal deformation in the SPF the grain is preliminarily coarsened, for example, by local heating [24]. Later at the SPF these zones are deformed to a lesser degree, which provides a relatively uniform thickness of the products. Information [25] on additional fining of grain in blanks by contact friction methods has appeared which significantly affects the accumulated strain [26]. In this case, the preliminary fining of the grain should be in the zones adjacent to the flange of the blank both when deep drawing [27, 28].

The use of solid lubricants or glass enamels partially increases the uniformity of blanks thinning at SPF $[2,3,7,12,29,30]$, reduces the oxidation and gas saturation of the surface layers of products. To eliminate the harmful effect of the hermetic clamping flange, it is proposed to use the end holder of the blank at SPF [5].

The non-uniform temperature field (NUTF) in the blanks at SPF is provided by creating a temperature gradient either over the depth of the die or over the surface of the blank [3, 24, 31]. Lowering the temperature in the most thinning zones of the blank inhibits their deformation at SPF in the NUTF, providing a more uniform thickness of the product.

Each ways to control the blank's metal flow at SPF has its drawbacks: the need for an additional forming tool, the reduction in SPF productivity, the cost of preparing the structure, the application and removal of lubricant, etc. We have proposed a new method for regulating of the metal flow at SPF by applying the thermally unstable coatings (sublimates) onto the sheet blank, which, due to a given thermal effect on the blank, changes its temperature field and formed local thicknesses. This method and its application require careful study. The purpose of this work was to study new methods of SPF with the creation on the surface of STP blanks due to thermally unstable coatings.

\section{Methodology}

Blanks probed $R=46 \mathrm{~mm}$, thickness $S=0.9 \ldots 1.0 \mathrm{~mm} A M g 6 M$ alloy $(\mathrm{Fe} \leq 0.4 \%, \mathrm{Si} \leq 0.4 \%$, $\mathrm{Mn}=0.5 \ldots 0.8 \%, \quad \mathrm{Ti}=0.02 \ldots 0.1, \quad \mathrm{Al}=91.1 \ldots 93.68, \quad \mathrm{Cu} \leq 0.1, \quad \mathrm{Be} \leq 0.0002 \ldots 0.005$, $\mathrm{Mg} \leq 5.8 \ldots 6.8, \mathrm{Zn} \leq 0.2$ ) with a grain size $15-20 \mu \mathrm{m}$. As thermally unstable coatings used ammonium chloride with sublimation temperature $t_{c}=338^{\circ} \mathrm{C}$ and ammonium iodide $\left(t_{c}=\right.$ $404^{\circ} \mathrm{C}$ ). The latent heat of transformation of the above substances was 330 and $355 \mathrm{~kJ} / \mathrm{kg}$, respectively.

Coating in the form of a supersaturated aqueous solution hit on preparations by spray stencils using a spray bottle. The uneven distribution of the thickness of the coating at first approximated by linear function $y=A(h / R)-B$ in the range $0.16 \leq(h / R) \leq 1 \quad(r$ - current distance from flange blank to the centre; $A, B$ - indices of approximation). Close to the linear distribution of the thickness of the coating was due to the technical abilities of the spray and the limited size of the blank. 
Effect of sublimation of ammonium from the surface of the blank thickness products studied for example free blow-molding of crowns with a relative height of $H=0.6 \ldots 1.0$ ( $H=h / R$, where $h$ is the absolute height of the crown) in hard- pinched flange. Blank modeled compressed air pressure up to $0.6 \mathrm{MPa}$ at temperatures $450 \pm 10^{\circ} \mathrm{C}$, i.e. within the temperature range of superplastic forming alloy $\operatorname{AMg} 6 M[2,3]$. The thickness of the blank and sublimates on its surface was measured at BMI-1 microscope. Variability of thickness of the crowns has been shaped by indicator:

$$
S=\frac{S_{\max }-S_{\min }}{S_{p}},
$$

where $S_{\max }, S_{\text {min }}$ - respectively the maximum and minimum wall thickness of the crown; $S_{p}$ - shell's wall thickness determined conditions of perfectly uniform deformation.

Spreading of thinning membranes evaluated the relative thickness of $S / S_{p}$ ( $S$ - wall thickness of the crown at this point).

On Fig. 1 the scheme of forming crowns with a sublimation coating.

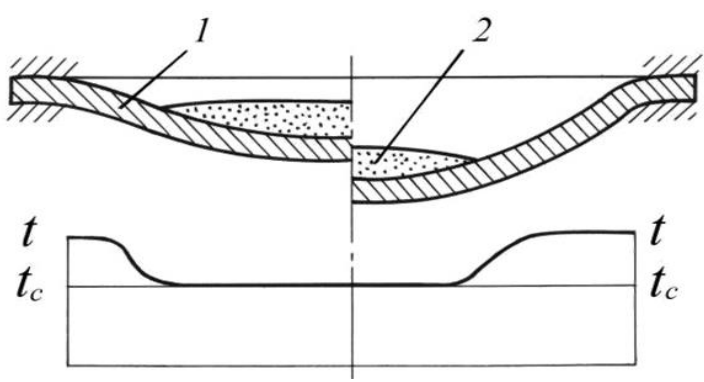

Fig. 1. Scheme of pneumoforming of crown with subliming coatings: 1 - blank; 2 - coating

The coated blank was heated prior to forming. Upon reaching temperature sublimation the layer of sublimation risen and stabilized temperature plots the blank underneath it at the level of $t_{c}+(20 \ldots 30)^{\circ} \mathrm{C}$, while free from coating the surface of the blank would be heated to the optimal temperature forming the first $t$. stage of the process was characterized by low temperature most part blanks, except the ring zone $(0 \leq r / R \leq$ $0.2 \ldots 0.45)$ from the flange. Thus provided the most suitable temperature deformation of peripheral sites. As the blow-shell superplastic forming mode distributed at stations presets, am from sublimate, which resulted in a rise in temperature from $t_{c}+(20 \ldots 30)^{\circ} \mathrm{C}$ to $t$. Hence, inhibition of thinning the blank in time zones carried out in proportion to the reduction of wall thickness during isothermal stamping. First way was carried out on the alloy $\mathrm{Zn}$-22Al (Al: $22 \mathrm{wt} . \%)$ [3].

In this work has been improved [3]. Shell height $H<0.3 \ldots 0.4$ is characterized by sufficient uniform wall thickness [3, 16, 18], therefore, in the initial stages of forming exercised without sublimation coating. For this changed partial pressure above the surface of the sublimate in accordance with the equation of the Clausius-Clapeyron. In the first stages of molding to save sublimate created over its surface pressure, ensuring inequality $t_{c}>t$. Sublimation was virtually non-existent, and the temperature of all sections of the blank has been tweaked. On reaching the limit crown height of $H=0.2 \ldots 0.3$ pressure over sublimate fell to providing the required temperature difference across the section of the blank while sublimation coating. 


\section{Result and discussion}

The Fig. 2 presents the results of forming hemispheres at a pressure of $0.4 \mathrm{MPa}$. The most uniform wall thickness in semispherical granules was achieved with a different distribution of chloride and ammonium iodide layer on the surface of the blank (see table). Approximately the same thermal effect of sublimation coating temperature difference $t-t_{c}$ for ammonium chloride amounted to $100 \ldots 115^{\circ} \mathrm{C}$ but for ammonium iodide - total $40 \ldots 50^{\circ} \mathrm{C}$, which necessitated more intense sublimation of the first sublimates and as a consequence increasing their mass.

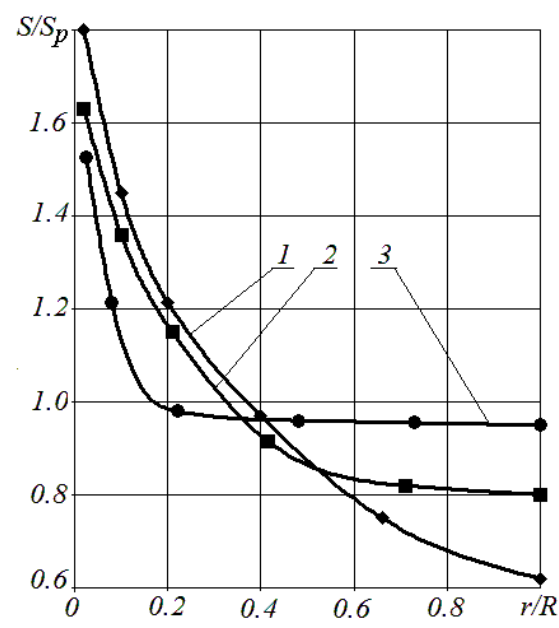

(a)

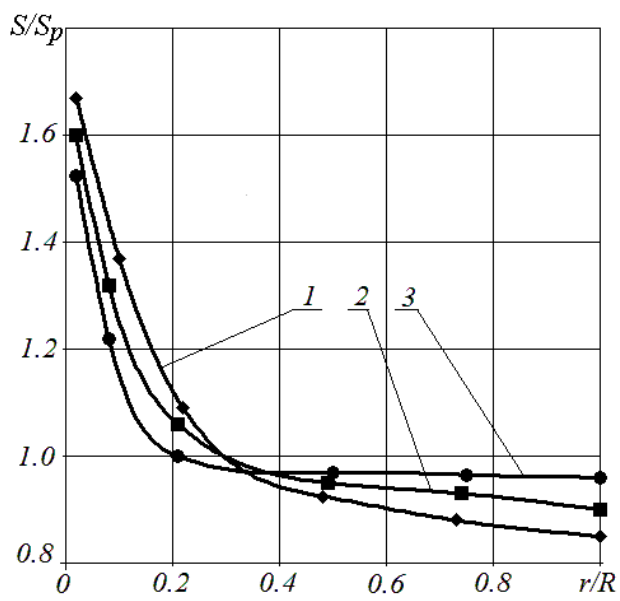

(b)

Fig. 2. Distribution of thinning the contour of the hemispheres, formed using sublimates: (a) 1 - isothermal SPF; 2, 3 - SPF with $\mathrm{NH}_{4} J$ and $\mathrm{NH}_{4} \mathrm{Cl}$ coatings; (b) 1, 2 - SPF with initiation of sublimation of $\mathrm{NH}_{4} \mathrm{Cl}$ at $\mathrm{H}=0.2$ and $\mathrm{H}=0.3 ; 3$ - sublimation of $\mathrm{NH}_{4} \mathrm{Cl}$ with the onset of SPF

Thickness variability of hemispheres on their working surfaces defined by the range $0.2 \leq r / R \leq 1$, was reduced by $40 \ldots .50 \%$. The best result obtained for hemispheres, formed in sublimation ammonium chloride from their surface, due to the fact that in this case, a higher temperature difference across the section of the blank at increasingly contributed to the braking strain pole shell zones.

Table. Parameters of forming hemispheres with sublimation coatings

\begin{tabular}{|c|c|c|c|c|c|}
\hline \multirow{2}{*}{$\begin{array}{c}\text { Coating } \\
\text { type }\end{array}$} & $\begin{array}{c}\text { Beginning of } \\
\text { sublimation }\end{array}$ & \multicolumn{3}{|c|}{ Approximating function $\boldsymbol{y}$} & \multirow{2}{*}{$\Delta S, \boldsymbol{\%}$} \\
\cline { 2 - 5 } $\mathrm{NH}_{4} \mathrm{Cl}$ & $H$ & $B$ & Range mensuration $r / R$ & \\
\hline \multirow{3}{*}{$\mathrm{NH}_{4} J$} & $H \geq 0$ & 12.5 & 4.0 & $0.32 \ldots 1.0$ & 10 \\
\cline { 2 - 5 } & $H \geq 0,3$ & 12.3 & 4.9 & $0.4 \ldots 1.0$ & 16 \\
\cline { 2 - 5 } & $H=0$ & 8.9 & 2.7 & $0.46 \ldots 1.0$ & 26 \\
\hline Is absent & - & - & - & $0.3 \ldots 1.0$ & 34 \\
\hline
\end{tabular}

Analysis of graphs in Fig. 2a it follows that to resist deformation of the blank clamping flange hard plots has more impact than a change of temperature. In zones of flange $0 \leq r / R \leq 0.2$ variety of thickness reached $30 \ldots 60 \%$ and increased with decreasing temperature difference to be created. However, a large number of shells of the flange with the well-adjoined zones removed on subsequent operations, so the big difference of thickness on peripheral sites shells on a working surface thickness of products is not 
affected. If the presence of the flange in the shells on the design considerations necessarily, usually flange during operation of products designed for the perception of effort, and then it increased against the average thickness is a positive factor. For crowns with a height of $0.6 \ldots 1.0$ variety of thickness was reduced to $4 \ldots 10 \%$ on the working surface.

On Fig. $2 b$ and table presents the results of experiments on superplastic forming of shells with sublimate. In experiments at the initial stages of forming increased pressure over the surface of ammonium chloride up to $0.6 \mathrm{MPa}$ when pressure difference on both sides of the blank $0.4 \mathrm{MPa}$. In this case the temperature of sublimation increased coverage to $470 \ldots 480^{\circ} \mathrm{C}$ and sublimation of it is absent. When the shell reached a given intermediate height, the pressure on both sides was lowered to $0.6 \mathrm{MPa}$. Thus initiated distillation coverage because its sublimation temperature at normal pressure $t_{c}=338^{\circ} \mathrm{C}$. Fig. $2 \mathrm{~b}$ shows that there is a equable enough thinning of the shells, although the thickness of the products exceeds the similar index achieved in previous experiments. When implementing the investigated methods of SPF with thermally unstable substances, it is advisable to use equipment for molding thermoplastics with an airborne suction system, since in some cases the products of sublimation of coatings are toxic.

\section{Conclusions}

1. In the case of superplastic forming of shells, the variability of walls thickness can be reduced by creating an uneven temperature field along the workpiece surface during forming. In particular, SPF spherical shells are advisable to perform with simultaneous sublimation of sublimates covered on the central zones of the blank.

2. The regulation of the thermally unstable coatings sublimation intensity should be carried out by changing the partial pressure over the sublimate, which changes the temperature and, consequently, the intensity of its sublimation.

3. The sublimate sublimation temperature should be much lower than the SPF temperature. Sublimation of coating should begin upon reaching the height of the formed shell equal $20 \ldots 30 \%$ of the final shell height.

\section{References}

1. Langdon T.G., Journal Materials Science, 44 (22), 5998-6010 (2009).

2. G. Giuliano, Superplastic Forming of Advanced Metallic Materials: Method and Applications (Woodhead Publishing Ltd, 2011).

3. A.S. Anishchenko, Izotermicheskaja $i$ sverhplasticheskaja deformacija metallov (Saarbrücken: LAMBERT Academic Publishing, 2014), in russ.

4. V. Kukhar, V. Burko, A. Prysiazhnyi, E. Balalayeva, M. Nahnibeda, East-European Journal of Enterprise Technology, 3/7(81), 53-61 (2016), DOI: 10.15587/17294061.2016.72063.

5. V. Kukhar, V. Artiukh, A. Prysiazhnyi, A. Pustovgar, E3S Web of Conference, 33, 02031 (2018), DOI: 10.1051/e3sconf/20183302031.

6. G.F. Wang, K.F. Zhang, D.Z. Wu, J.Z. Wang, Y.D. Yu, Journal of Materials Processing Technology, 178, 24-28 (2006), DOI: 10.1016/j.jmatprotec.2005.10.005.7.

7. K.F. Zhang, G.F. Wang, D.Z. Wu, Z.R. Wang, Journal of Materials Processing Technology, 151 (1-3), 54-57 (2004), DOI: 10.1016/j.jmatprotec.2004.04.008.

8. J. Sieniawski, M. Motyka, Journal of Achievements in Materials and Manufacturing Engineering, 24 (1), 123-130 (2007). 
9. A.S. Anishchenko, A.P. Andryushchenko, Soviet Engineering Research, 5, 54-55 (1991).

10. M.V. Kovalevich, A.A. Klimova, Jelektronnyj Zhurnal "Trudy MAI”, 38, 21-28, 2010, in russ.

11. G.Jr. Luckey, P. Friedman, K. Weinmann, Journal of Materials Processing Technology, 209 (4), 2152-2160 (2009), DOI: 10.1016/j.jmatprotec.2008.05.019.

12. P.A. Friedman, G. Luckey, High-Temperature Lubricants for Superplastic Forming of Metals (Woodhead Publishing Limited, 2011).

13. E.M. Seledkin, V.D. Kuhar', K.Ju. Apatov, Izvestija Vysshih Uchebnyh Zavedenij, Cvetnaja Metallurgija, 4, 52-56 (2010), in russ.

14. A.A. Shitikov, Kuznechno-Shtampovochnoe Proizvodstvo - Obrabotka Materialov Davleniem, 2, 34-40, (2014), in russ.

15. E.V. Panchenko, K.A. Turkin, R.O. Semjonova, R.N. Kol'zjaev, Avtomatizacija i Sovremennye Tehnologii, 1, 3-4 (2009), in russ.

16. C.A. Picard, Matériaux \& Techniques, 76 (1-2) 14-39 (1988).

17. A. Dutta, Materials Science and Engineering A, 371 (1-2), 79-81 (2004).

18. Y.H. Kim, Lee J-M., S.S. Hong, Journal of Materials Processing Technology, 112 (23), 166-173 (2001), DOI: 10.1016/S0924-0136(00)00880-3.

19. J.H. Yoon, H.S. Lee, Y.M. Yib, Y.S. Jang, Journal of Materials Processing Technology, 187-188, 463-466 (2007), DOI: 10.1016/j.jmatprotec.2006.11.187.

20. B.H. Cheong, J. Lin, A.A. Ball, Journal of Materials Processing Technology, 134 (1), 10-18 (2003), DOI: 10.1016/S0924-0136(02)00216-9.

21. D.A. Kitaeva, G.E. Kodzhaspirov, Ya.I. Rudaev, METAL 2016, Brno-Ostrava: TANGER, 1426-1431 (2016).

22. A.S. Anishchenko, Metallovedenie i Termicheskaya Obrabotka Metallov, (Metallography and Heat Treatment of Metals), 2, 31-32 (1996).

23. V.V. Kukhar, O.V. Vasylevskyi, Metallurgical and Mining Industry, 3, 71-78 (2014).

24. V.V. Kukhar, Metallurgical and Mining Industry, 6, 122-132 (2015).

25. R.S. Babu, Kumar S.V.S., L. Karunamoorthy, M.G. Reddy, Materials and Design, 53, 338-348 (2014).

26. V. Kukhar, V. Artiukh, A. Butyrin, A. Prysiazhnyi, Advances in Intelligent Systems and Computing, Springer, 692, 201-211 (2018), DOI: 10.1007/978-3-319-70987-1_22.

27. E. Balalayeva, V. Artiukh, V. Kukhar, O. Tuzenko, V. Glazko, A. Prysiazhnyi, V. Kankhva, Advances in Intelligent Systems and Computing, Springer, 692, 220-235 (2018), DOI: 10.1007/978-3-319-70987-1_24.

28. V. Kukhar, E. Balalayeva, O. Nesterov, MATEC Web of Conferences, 129, 01041, (2017), DOI: 10.1051/matecconf/201712901041.

29. A.S. Anishchenko, Yu.V. Feofanov, A.B. Bogun, Chemical and Petroleum Engineering, 11, 33-35 (1992).

30. P. Wood, M.J. Qarni, A. Rosochowski, Key Engineering Materials, 473, 532-539 (2011), DOI: 10.4028/www.scientific.net/KEM.473.532.

31. V. Kukhar, A. Prysiazhnyi, E. Balalayeva, O. Anishchenko, Modern Electrical and Energy System, IEEE, Kremenchuk, 404-407, (2017), DOI: 10.1109/MEES.2017.8248945. 